\title{
The computer as experimenter in social psychological research*
}

\author{
DAVID J.STANG $\dagger$ \\ Queens College, CUNY. Flushing, New York 11367 \\ and \\ EDWARD J. O'CONNELL \\ Syracuse University, Syracuse, New York 13210
}

\begin{abstract}
The effects of familiarity and exposure paradigm on evaluative meaning were investigated in four experiments involving 161 Ss. A DEC PDP-10 computer linked to a VB10-C display screen for I/0 assigned Ss to condition, presented instructions, tested Ss' understanding of the instructions, generated and displayed stimuli in various frequencies, and obtained evaluative ratings of the stimuli. Problems encountered, Ss' reactions, and current and possible use of the computer in social psychological research are discussed.
\end{abstract}

\section{THE COMPUTER AS EXPERIMENTER: AN EXAMINATION OF THE EFFECTS OF EXPOSURE AND FREQUENCY ON EVALUATIVE MEANING OF THE STIMULUS}

In the past few years, a growing body of research has emerged on the relationship between exposure frequency and changes in the evaluative meaning of the stimulus. Although this research dates back to theoretical propositions advanced by Fechner (1876) and a sizable body of research done in the early part of this century (e.g., Gilliland \& Moore, 1924; Maslow, 1937; Pepper, 1919; Valentine, 1914; Verveer, Barry, \& Bousfield, 1933; Washburn, Child, \& Abel, 1927), the current interest in the area has been largely stimulated by an impressive recent monograph by Zajonc (1968). Zajonc contended that repeated exposure of a novel stimulus was a sufficient condition for enhancement of one's attitude toward that stimulus. Much subsequent research by social psychologists in the area has focused on the generality of this sweeping hypothesis.

Emerging from these investigations are several important limiting factors. First, it seems that repeated exposure is most likely to result in enhancement of the evaluative meaning of the stimulus when a delay of several minutes or more occurs between exposure and rating of the stimulus (Stang, 1973a, b, in press a) and when the stimuli are fairly novel and meaningless on first exposure to the $S^{1}$ (Hamid, 1972). A variety of theories

\footnotetext{
* Much of this paper is based on research conducted as part of the first author's doctoral dissertation research, under the direction of the second author. Stang wishes to thank Sidney Arenson, Clive Davis, William Meyer, Marshall Segall, and Daniel Smothergill for comments on earlier drafts of this manuscript. Appreciation is extended to Marcy Perl for assisting in the data collection on current uses of the computer, and especially to Paul Demong and Tom Mattson for technical support in the experiments reportes herein.

+ Requests for reprints should be sent to David J. Stang. Psychology Department, Queens College, CUNY, Flushing, N.Y. 11367.
}

have been proposed to account for the phenomenon (reviewed in Stang, 1973 c, see also Stang, in press a \& b), and some researchers are now turning their attention to applied problems. ${ }^{2}$

One theoretical question which seeks clarification is the relationship between exposure paradigm, exposure frequency, and evaluative change. Two basically different types of exposure sequence have been employed in previous experiments, to be referred to as distributed exposure (DE) and massed exposure (ME). In $\mathrm{DE}$, the presentation of each stimulus is of a constant, relatively brief duration, but some stimuli are presented more frequently than others, and the presentations of all the stimuli are randomly interspersed. Under ME, however, each stimulus is presented once for some variable interval or repeatedly in succession until the total exposure duration is attained, before the next stimulus is presented. Typically, the literature reports that $\mathrm{DE}$ results in evaluative meaning being a positive linear function of $\log$ exposure frequency, while ME produces an inverted U-shaped function, and a statistical analysis of the literature (Stang, 1973a) confirms this observation. However, this analysis of the literature indicated that the effect of exposure paradigm had been confounded with the variable of rating delay; ME has usually been followed by immediate ratings, whereas DE is usually followed by delayed ratings. This confounding has also occurred in those few studies which have purported to directly compare DE and ME: Harrison and Crandall (1972a, b) and Hamid (1972) both interposed an interval between exposure and rating in their $\mathrm{DE}$ conditions. The experiments reported here compare the evaluative consequences of repeated exposure under DE and ME with no interval between exposure and rating phases.

The four experiments used the computer to assign Ss to conditions, generate and display stimuli, and request ratings. There are a number of reasons why the 


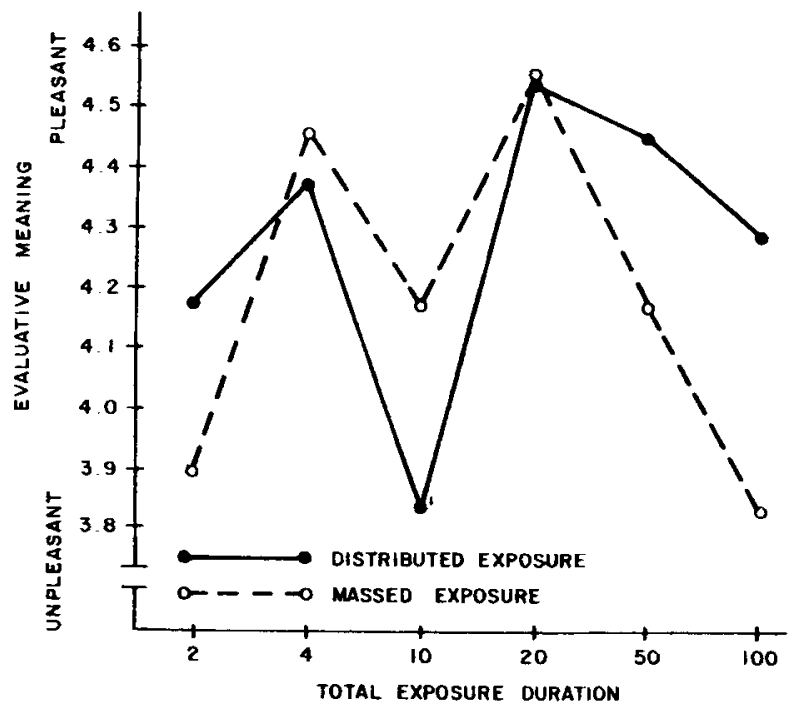

Fig. 1. Rated pleasantness as a function of exposure frequency/duration and exposure paradigm in Experiment $l$.

computer was used to conduct these experiments. One principle advantage was the greater replicability of experiments, providing greater justification for statistical and graphic comparisons of the results of the different experiments in the series. As McClintock (1969) notes, "The advantage of the computer derives from its inherent flexibility in presenting a great variety of stimuli and measuring an equally great variety of responses. At the same time, the machine permits greater standardization, control, and reliability of experimental procedures [p. 286]." As Zajonc (1965) has emphasized, this standardization and control is typically lacking in social psychological experiments. An added advantage of the improved control over the experiment is suggested by Utall (1969): "Typically, the computer-obtained results seem to have less variance for the same amount of data [p. 203]." Other advantages are also worth considering. The possibility of E effects (Rosenthal, 1964) is reduced when the computer is used; according to Rapoport (1964), Ss regularly find it a more satisfying and confidence invoking experience to interact with a computer-controlled display than with a human-controlled display. Messick and Rapoport (1964) review a number of these advantages.

\section{Experiment I}

\section{Method}

Overview. Thirty-four Ss viewed simple and complex random walks on a computer display screen, and rated them for pleasantness. Exposure paradigm (DE or ME) was a between-Ss variable, while exposure frequency and stimulus complexity were within-Ss variables.

Subjects. Eighteen male and 16 female Ss, drawn from the introductory psychology S pool at Syracuse University, were randomly assigned to either a $\mathrm{DE}$ or $\mathrm{ME}$ condition.
Stimuli. Stimuli consisted of three practice and 12 test patterns. The 12 test patterns (random walks) were created at two levels of complexity: "simple" (5-10 lines) and "complex" (65-70 lines). These stimuli, as well as instructions to $S$, were presented to $S$ at a DEC VB10-C display console. A new set of patterns was generated for each $S$.

The principle reason for using two levels of stimulus complexity, and for what amounted to randomly sampling from the universe of all possible random walks at those levels of complexity was to extend the generality of the results. In theory, this provides somewhat more justification for making generalizations about random walks as a class of patterns than does the more common procedure of using fixed stimuli and generalizing anyway. The ability of the computer to effortlessly generate and display an endless variety of truly random walks was a major asset to these studies.

Rating Scale. In this experiment, a 7-point pleasant-unpleasant rating scale was used, with six scale values also bearing the qualifiers "very," "guite," or "slightly," and the midpoint labeled "neither pleasant nor unpleasant." These scale values were used as labels for the numbers 1-7 on the display console.

Procedure. ${ }^{3}$ All interactions in the experiment were between $S$ and the display screen. E was present to answer any questions, but otherwise remained seated out of sight of $S$. The first message to appear on the screen for all Ss was: "In this experiment, you will be asked to make some judgments using a 7-point rating scale. The scale appears below, and you should learn to use it now..." Ss were tested on their ability to match the appropriate number on their keyboard with the corresponding semantic quantifiers presented on the screen. When $S$ had made seven consecutive correct responses and when S's last response was made in $4 \mathrm{sec}$ or less, the program permitted $S$ to proceed to the practice phase of the experiment. In the practice phase, Ss were given practice in viewing three typical patterns and rating them. Following the practice phase, the procedure differed for the two conditions.

The DE condition was similar to the typical DE experiment (e.g., Zajonc, 1968). Ss viewed the 12 stimuli at various frequencies and then rated them. Specifically, each $S$ viewed six simple and six complex random walks, one each at the frequencies of 1, 2, 5, 10, 25, and 50 exposures. Each exposure lasted for $2 \mathrm{sec}$ with an interexposure interval of less than .1 sec. The order in which stimuli were viewed was determined by systematic changes in assignment to randomly ordered slots.

The ME condition was similar to the typical ME experiment (e.g., Harrison \& Crandall, 1972a). Ss repeated viewing a stimulus for a certain total duration, rated it, viewed another stimulus, etc. As in the DE condition, each $\mathrm{S}$ viewed 12 stimuli, a simple and a complex one at each of the total durations of 2 , $4,10,20,50$, and $100 \mathrm{sec}$. To achieve these total durations, each stimulus was repeatedly exposed for 2 sec per exposure until the total duration was attained.

\section{Results}

The results of the ANOVA indicate a significant $(\mathrm{F}=$ 2.358 , df $=5 / 86, p<.05)$ main effect of exposure duration resembling an $\mathrm{M}$. The interaction of complexity and exposure paradigm was significant $(\mathrm{F}=5.028$, $\mathrm{df}=$ $1 / 30, p<.05)$ and is the result of simple stimuli being rated nonsignificantly more pleasant under $D E$, while complex patterns were rated nonsignificantly more pleasant under ME. A recent theory (Stang, in press a) might suggest that the simple stimuli induced satiation 


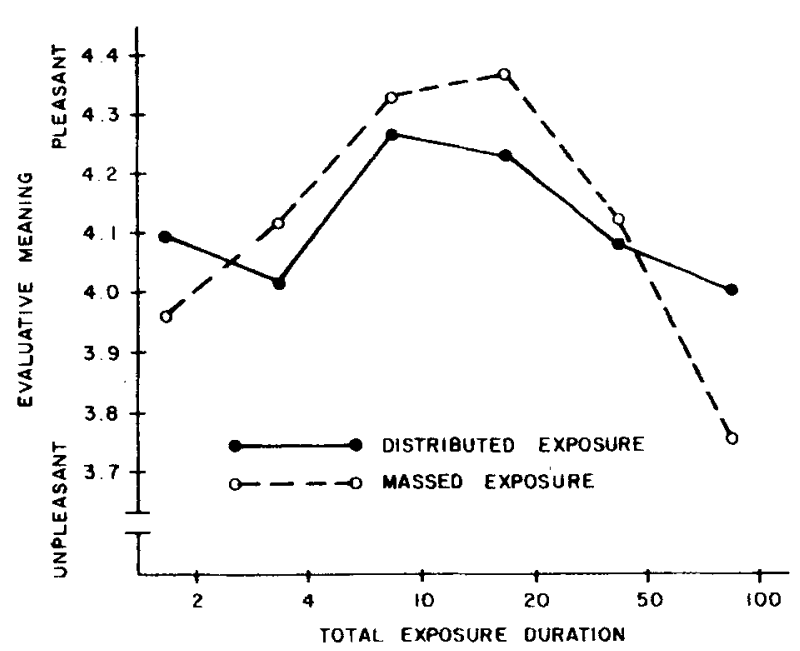

Fig. 2. Rated pleasantness as a function of exposure frequency/duration and exposure paradigm in Experiment II.

under ME, while the complex stimuli were not learned well enough to enhance affect under DE.

The interaction that was sought in the experiment failed to materialize: there was no interaction of exposure duration and exposure paradigm $(\mathrm{F}=1.005 \mathrm{df}$ $=5 / 86, \mathrm{p}<.25$ ). Figure 1 indicates that the $\mathrm{DE}$ and $\mathrm{ME}$ curves are similar in appearance, diverging slightly but not significantly at 50 and $100 \mathrm{sec}$ of exposure ( 25 and 50 repeated 2-sec exposures under DE). This divergence is expected from previous studies, although the unpredicted low ratings at 10 exposures remains unexplained.

\section{Experiment II}

The second experiment essentially provided a replication of Experiment I, with one difference: in order to ensure that $\mathrm{Ss}$ would be able to discriminate the stimuli in the first experiment, the intensity and density of points which comprised the lines of the patterns had been varied across patterns. Intuitively, it seemed possible that those differences between the patterns might be responsible for a large proportion of the variance in evaluative ratings, masking any variance contributed by exposure duration, paradigm, etc. Consequently, all stimuli in Experiment II comprised points having the same intensity and density: bright, solid lines. It was hoped that this change might be sufficient to detect a significant Paradigm by Duration interaction.

\section{Method}

Ss were 55 students taken from the same population as Ss in Experiment I and randomly assigned to two conditions, designated DE and ME. The procedure was identical to that of Experiment I.

\section{Results}

Before tabulating the data, the ratings of three Ss were discarded because they had given all stimuli the same ratings. This left 26 remaining $S$ s in each condition. An ANOVA, using the same factors as Experiment I, produced similar results. This time, the main effect of exposure frequency resembled an inverted $U$ (see Fig. 2) but was not significant at conventional levels $(\mathrm{F}=1.872$, $\mathrm{df}=5 / 250, \mathrm{p}<.1)$.

As in Experiment $l$, the Paradigm by Duration interaction was not significant $(F=.390)$, and while $\mathrm{ME}$ produced the inverted $U$ as expected, DE did not result in a linear enhancement of affect with repeated exposure. Rather, it produced only a slight flattening of the inverted $U$ produced by ME. The difference between the paradigms at $100 \mathrm{sec}$ exposure was again as reported in the previous literature, but not significant $(F<1)$.

\section{Experiment III}

Experiments I and II failed to support the hypothesis that exposure paradigm interacts with exposure frequency given no delay between exposure and evaluative rating. It is possible, however, that the differences between stimuli were still so great along the complexity dimension that Ss were responding only to this dimension, and any effect of frequency under DE was being masked by stimulus differences. Previous studies which have found linear enhancement of affect with repeated exposure under DE have used stimuli which were very similar to each other. Thus, a final attempt to obtain a difference between the paradigms given patterns as stimuli was attempted in which stimuli are all relatively homogeneous. The level of complexity chosen for Experiment III was one that seems to be closer to that of the ideograph, a stimulus often used in recent studies in this area.

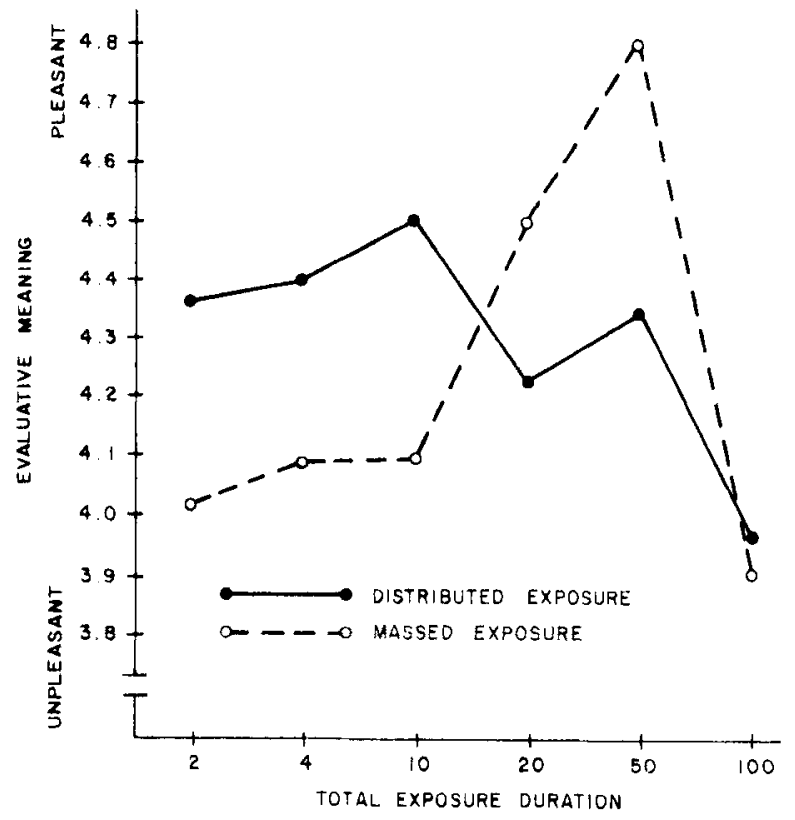

Fig. 3.Rated pleasantness as a function of exposure frequency/duration and exposure paradigm in Experiment III. 


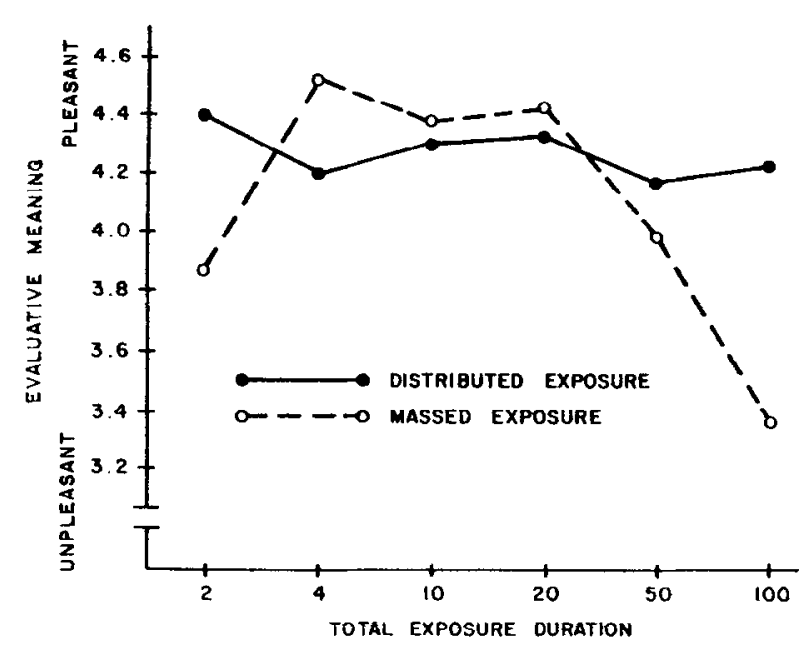

Fig. 4. Rated pleasantness as a function of exposure frequency/duration and exposure paradigm in Experiment IV.

\section{Method}

Ss were 26 students taken from the same population as Ss in Experiments I and II and randomly assigned to two conditions. Stimuli were generated in the same fashion as in Experiment II, except that all stimuli were relatively simple, each being composed of four lines. The experimental procedure was identical to that of Experiment II, with two exceptions: (a) Ss were not given practice in using the rating scale or in rating practice stimuli; (b) all Ss were run in both DE and ME. One half of the Ss first saw 12 patterns under DE, then saw another 12 under ME, while the other half of the Ss underwent the exposure in reverse sequence. Thus, each $S$ was exposed to and rated a total of 24 different simple patterns.

\section{Results}

As in Experiments $I$ and II, an ANOVA was performed on the data. This analysis revealed that neither exposure sequence (DE vs ME first) nor paradigm (DE vs ME) had significant main effects on pleasantness ratings, but the interaction between these two variables was significant $(F=4.714$, df $=1 / 24$, $\mathrm{p}<.05$ ), with nonsignificantly more pleasant ratings occurring toward the end of the experiment.

As in the first two experiments, the main effect of exposure duration was marginally significant $(p=.077)$, again taking the form of an inverted $U$ (see Fig. 3) and, as in the first two experiments, the interaction of paradigm and duration was not significant. Again while ME produced the inverted $U$ function, $D E$ did not result in enhancement of affect with repeated exposure. Further, there was actually convergence of the two functions at $100 \mathrm{sec}$ exposure, in contrast to the predictions concerning paradigm effects. Other interactions were observed which are not germane to the present discussion, and are reported elsewhere (Stang, 1973b).

\section{Experiment IV}

The previous three experiments each failed to show a linear enhancement of affect under $\mathrm{DE}$, although something resembling an inverted $\mathrm{U}$ resulted from $\mathrm{ME}$ in each case. Two possible explanations are suggested. First, it is possible that random walks do not easily show enhancement of affect with repeated exposure (see Stang, 1973a). This question is examined in the fourth experiment, in which different stimuli and the same experimental design are employed. The other possibility, of course, is that an interval between exposure and rating really is necessary for enhancement of affect to occur with repeated exposure. This conclusion will be tentatively drawn if the results of Experiment IV resemble those of Experiments I-III.

To provide assurance that the inverted $U$ curve obtained is a result of the stimuli used rather than the absence of a rating delay of some other methodological artifact, it is necessary to demonstrate that the present method can produce the linear increase characteristic of most DE experiments when other stimuli are used.

\section{Method}

Ss were 46 students drawn from the same population as $\mathrm{Ss}$ in Experiments I, II, and III and were randomly assigned to two conditions as in Experiment III. Stimuli were 24 Turkish adjectives. The procedural differences between Experiment IV and Experiment III are noted below.

First, as an efficiency measure, Ss were scheduled to run in groups of two. The data from each pair of Ss thus run was averaged before the ANOVA was performed, since these data may have lacked some of the independence of data from Ss run at different times. Secondly, because new stimuli were not generated for each $\mathrm{S}$, the 24 stimuli were counterbalanced against each of the six durations, two orders, and two exposure paradigms, such that each stimulus was exposed equally of ten at each level of these variables. A third difference between this experiment and previous experiments, necessitated by the economy of running two Ss at once, was that rather than enter their ratings directly on the Teletype, Ss used a rating booklet.

\section{Results}

Data were analyzed by sorting the ratings obtained into the appropriate cells of two 24 by 12 matrices, the two matrices representing the two conditions, the 24 rows representing the 24 Turkish words, and the 12 columns representing six frequencies at DE and six durations at ME. The means of these 576 cells were then obtained. Results of the ANOVA indicated that, as in the previous experiments, exposure duration was an influential variable $(F=3.610, \mathrm{df}>5 / 230, \mathrm{p}<.01)$, taking the form of an inverted $U$, as in the first three experiments. Further, but unlike the previous experiments, the interaction between exposure paradigm and exposure duration was significant $(\mathrm{F}=3.11$, df $=$ $5 / 23, p<.01$ ). This interaction (see Fig. 4) seems to be the result of $\mathrm{ME}$ producing an inverted $\mathrm{U}$ and $\mathrm{DE}$ producing essentially a horizontal line.

\section{Discussion and Summary}

Although results were often not statistically significant in these experiments, a graphic summary of these experiments appears useful. Figure 5 simply provides a summary of the main effects of $\mathrm{DE}$ and $\mathrm{ME}$, averaging accross the four experiments. It is clear that ME tended to produce an inverted-U-shaped 


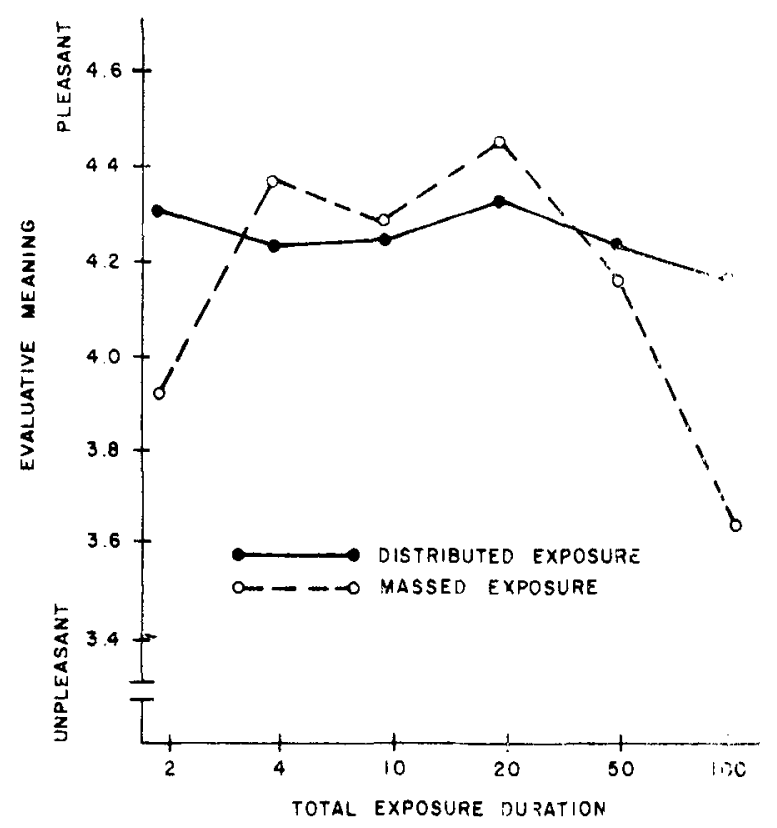

Fig. 5. Interaction of exposure paradigm and duration across patterns and Turkish words, Experiments I-IV.

function, while under $D E$, evaluative meaning was unrelated to exposure frequency. Pooling across exposure paradigms, Fig. 6 compared the average main effect resulting from random walks (Experiments I-III) with the main effect for Turkish words (Experiment IV). It is evident that both types of stimuli produced essentially the same main effects. One is led to the conclusion that under the present experimental conditions, the two types of stimuli had similar effects, while the two exposure paradigms had rather different effects.

One important problem which remains, however, is why DE did not produce the typical monotonic increase in evaluative meaning with repeated exposure. While it is quite possible that the absence of an interval between exposure and rating was the crucial variable, other methodological differences between the present studies and previous studies reported in the literature may be responsible. However, a fifth experiment reported elsewhere (Stang, in press a) has confirmed the importance of rating delay, using otherwise identical procedures. This fifth experiment revealed that with immediate ratings, stimuli are equally well recalled, and equally well liked, whereas with a delay of several minutes, frequency and recall covary, recall and evaluative meaning covary, hence frequency and evaluative meaning covary.

\section{THREE MINOR PROBLEMS ENCOUNTERED IN THE RESEARCH}

Three minor problems arose during the course of this research, and are outlined here mainly as forewarning to future on-line researchers.

The $\mathrm{E}$ had made the naive assumption that his $\mathrm{Ss}$ would be as skilled using the keyboard as he had become. This assumption was quite unrealistic, and even the few Ss who were experienced typists didn't understand the need for using the carriage return on the CRT. Consequently, a postexperimental questionnaire, built into the original program for Experiment I and requiring essay type answers had to be abandoned in favor of conventional dittoed questionnaires and handwritten responses. Good design in future research could include postexperimental questionnaires in multiple choice format. If skillfully written, and sequentially presented, multiple choice items could tease out such things as $S$ 's hypotheses and suspicions concerning the experiment.

Another problem arose with one S, and might occur under other experimental conditions more frequently. This $S$ apparently misunderstood the instructions, and responded before ratings were requested. Since the CPU cannot know when the display screen is finally doing what its doing, this problem does not seem to be easily dealt with, except by the presence of a human 0 or better instructions or more extended practice.

A third problem should be considered, and is possibly more serious than the preceding two. Toward the end of Experiment III, ratings tended to be nonsignificantly higher than at the beginning, suggesting that Ss were feeling more relaxed as they became more familiar with the apparatus and setting. Some comments made by Ss in their postexperimental questionnaires support this interpretation. For instance, one S wrote: "I found it foreign and demanding at first. However, as I became more familiar with it, it became a pleasant experience by its completion." An increase in rated (and experienced?) pleasantness as the experiment progresses has been found elsewhere (e.g., Swap, 1970; cf. Edney, 1972) and might be predicted by Zajonc's (1968) hypothesis noted earlier; the effects of the pleasantness of the rating context on ratings made has also been investigated (e.g., Maslow \& Mintz, 1956; Mintz, 1956; see also Phares \& Rotter, 1956; Messick \& Rapoport, 1964). These findings have implications for research dealing with factors affected by the experimental context. As Ss habituate to the strange environment, their behavior may substantially change. Habituation effects should be analyzed and reported, and to some extent may be controlled statistically through repeated measures of,

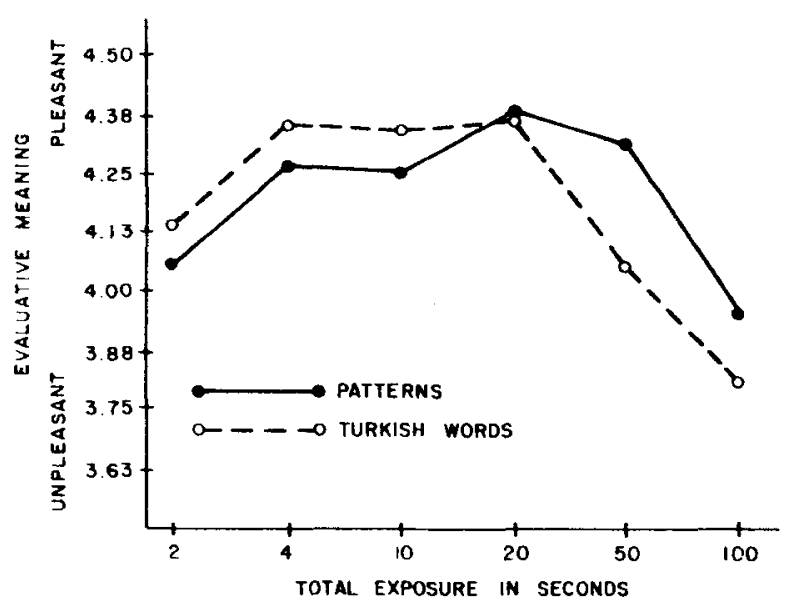

Fig. 6. Main effect of exposure duration across paradigms for patterns (Experiments I, II, and III; and Turkish, words, Experiment IV). 


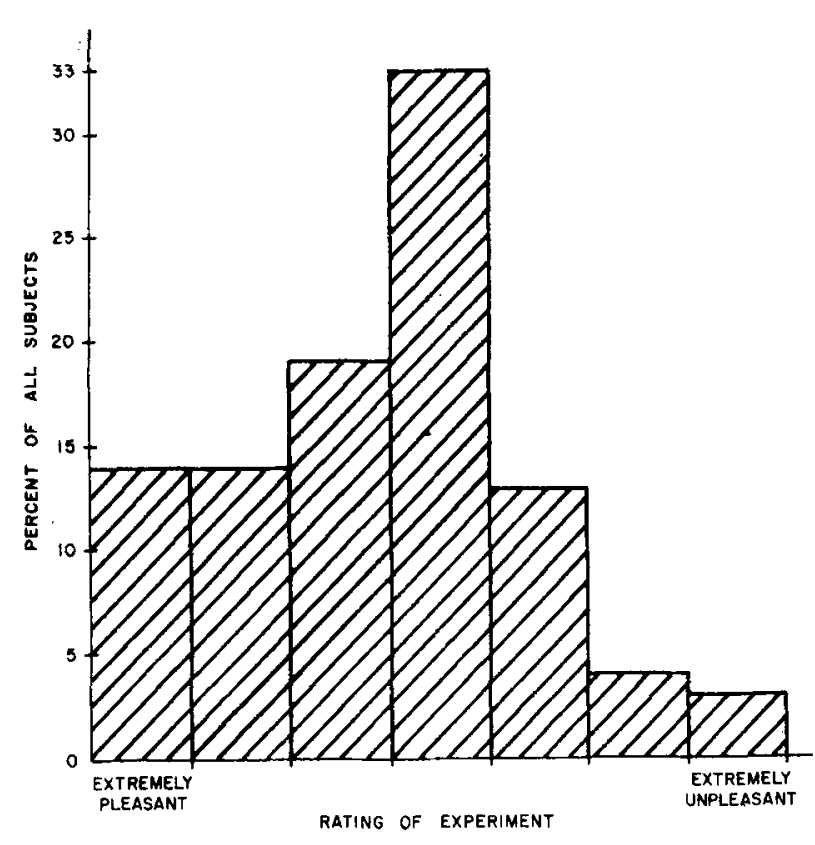

Fig. 7. Rated pleasantness of experiments.

e.g., "pleasantness of the experiment" and counterbalancing. Some habituation effects may be minimized by the experimental design: e.g., make the experimental setting as comfortable and relaxing as possible (e.g., the console might be located in a familiar environment such as a quiet office or lounge) and by providing an habituation or warm-up period in the design. In addition to controlling for habituation effects,

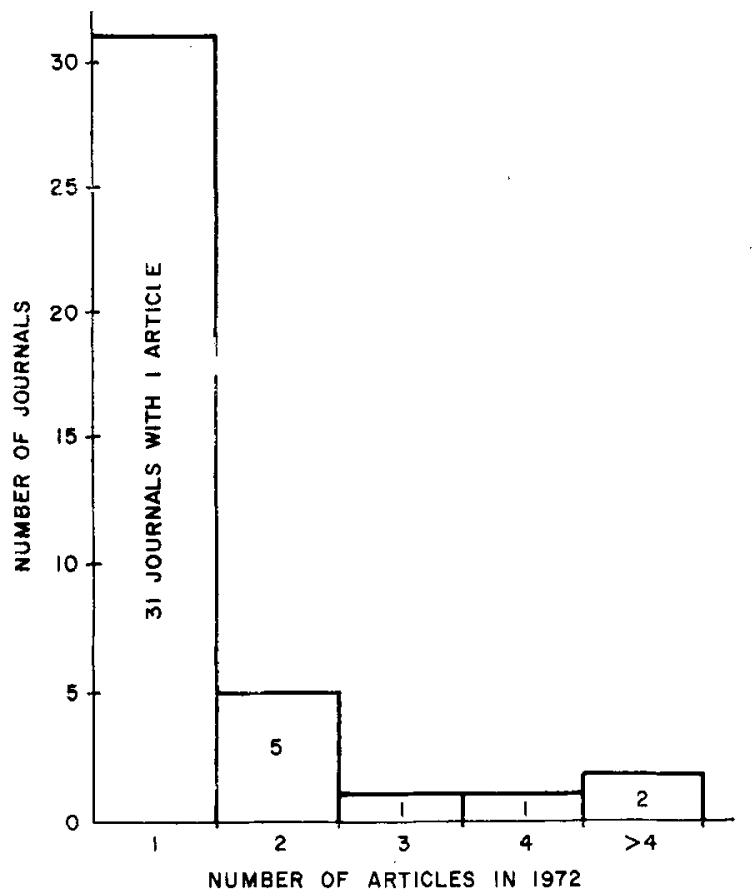

Fig. 8. Number of journals publishing various numbers of articles in 1972 related to psychological applications of computers, as cited in Psychological Abstracts. it would be worthwhile to directly study the effects of habituation to the experimental context as a methodological problem in research.

Regardless of how aroused Ss were at the start of the experiment, Ss were reporting at the end of the experiment that they found the experiences very pleasant. Their essay answers on the postexperimental questionnaire indicated this, and so did semantic differential ratings made of the "pleasantness of the experiment" (see Fig. 7). These findings are in agreement with Rapoport's (1964; Messick \& Rapoport, 1964) observations. Propogandists for the use of on-line computers in psychological research might use this finding, since an $E$ would presumably find pleasant an experiment his Ss also found pleasant.

\section{CURRENT USES OF THE COMPUTER IN PSYCHOLOGY AND SOCIAL PSYCHOLOGY}

The use of the computer as $\mathrm{E}$ in social psychological research seemed intuitively to us to be a relatively novel application. The analysis below supports this intuition and surveys the current uses of the computer in psychology.

The first task in defining current usage is to identify the major sources of papers dealing with computer applications to psychology. A survey of the literature was conducted to determine where articles on computer applications to psychology most commonly appear. A tally of citation frequency of journals containing articles on "computer" for Psychological Abstracts, 1972, was done. Analysis of these data revealed that Behavior Research Methods and Instrumentation published 19\% of these articles in 1972, Dissertation Abstracts published abstracts of $16 \%$, and 38 other journals published the remaining $65 \%$ of these articles, an average of 1.85 articles per year per journal, for those journals publishing at least one article on the topic that year. These data are depicted in Fig. 8 and resemble Allport's (1934) famous J-curve. This analysis also revealed that a number of the articles abstracted in Psychological Abstracts on the topic in 1972 (15\% of these) were written in foreign languages, the most common being French, Russian, and German. However, this search failed to locate one computer-related article in any of the social psychology journals (European Journal of Social Psychology, Journal of Experimental Social Psychology, Journal of Personality \& Social Psychology, Journal of Social Psychology, Representative Research in Social Psychology, Sociometry) for 1972.

Another interesting means of focusing on location of articles pertaining to applications of computers to psychology is to examine the number of citations under the general topic of "computers" in Psychological Abstracts as a function of time. Figure 9 indicates the absolute number of articles on computers referenced by Psychological Abstracts from 1953 through 1971, and this number as a proportion of all citations. It seems reasonable to assume that the average computer-related 


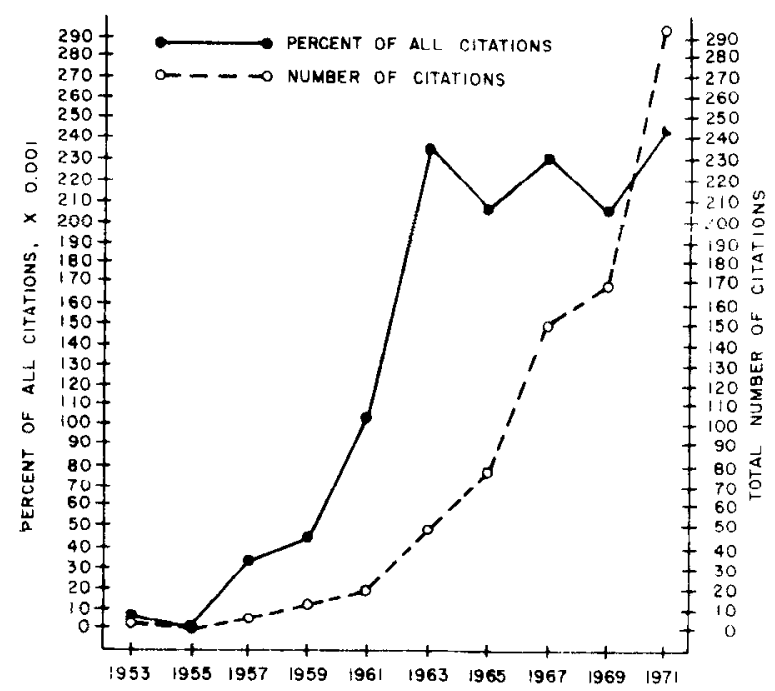

Fig. 9. Numbers of articles on computers cited in Psychological Abstracts and percent of total citations in Psychological Abstracts. article is referenced in Psychological Abstracts as often as the average noncomputer article. If so, citation frequency would be expected to be highly correlated with actual number of articles. As may be seen from Fig. 9, the absolute number of articles relating computers and psychology is of the form of a growth curve, beginning with one in 1953 (when "computer" was mispelled!) and almost doubling every 2 years since then. However, as a proportion of all articles in psychology, computer-related articles apparently approached an asymptote in 1963.

But what are these articles about? How was the computer used? A content analysis of Psychological Abstracts' references to computers was undertaken, similar to that recently done by Meltzer (1973). Table 1 summarizes the frequency per year of a number of different applications of computers to psychology. The only applications of the computer to social psychological research for these years involved simulations of social behavior and simulations of social

Table 1

Citations in Psychological Abstracts Pertaining to Computers, 1959-1971

\begin{tabular}{|c|c|c|c|c|c|c|c|c|c|c|c|c|c|c|c|c|}
\hline & \multicolumn{2}{|c|}{1959} & \multicolumn{2}{|c|}{1961} & \multicolumn{2}{|c|}{1963} & \multicolumn{2}{|c|}{1965} & \multicolumn{2}{|c|}{1967} & \multicolumn{2}{|c|}{1969} & \multicolumn{2}{|c|}{$\begin{array}{c}\text { Jan.-June } \\
1971\end{array}$} & \multicolumn{2}{|c|}{ Total } \\
\hline & $\mathrm{N}$ & $\begin{array}{l}\text { Per- } \\
\text { cent }\end{array}$ & $\mathrm{N}$ & $\begin{array}{l}\text { Per- } \\
\text { cent }\end{array}$ & $\mathrm{N}$ & $\begin{array}{l}\text { Per- } \\
\text { cent }\end{array}$ & $\mathrm{N}$ & $\begin{array}{l}\text { Per- } \\
\text { cent }\end{array}$ & $\mathrm{N}$ & $\begin{array}{l}\text { Per- } \\
\text { cent }\end{array}$ & $N$ & $\begin{array}{l}\text { Per- } \\
\text { cent }\end{array}$ & $\mathrm{N}$ & $\begin{array}{l}\text { Per- } \\
\text { cent }\end{array}$ & $\mathbf{N}$ & $\begin{array}{l}\text { Per- } \\
\text { cent }\end{array}$ \\
\hline Hardware & 0 & 0 & 0 & & 1 & 2 & 1 & 1 & 2 & 1 & 15 & 9 & 2 & 2 & 21 & 4 \\
\hline $\begin{array}{l}\text { Information storage } \\
\text { and retrieval }\end{array}$ & 2 & & 1 & & 1 & 2 & 1 & 1 & 10 & 117 & 6 & 31 & 5 & & & \\
\hline CAI: Instruction & 0 & 0 & 1 & 2 & 1 & 1 & 3 & 4 & 8 & 5 & 10 & 6 & 9 & 8 & 42 & 7 \\
\hline $\begin{array}{l}\text { CAI: Test preparation } \\
\text { and administration }\end{array}$ & 0 & 0 & 0 & 0 & 0 & 0 & 0 & 0 & 3 & 2 & 1 & 1 & 0 & 0 & 4 & 1 \\
\hline $\begin{array}{l}\text { CAI: Test scoring and } \\
\text { item analysis }\end{array}$ & 0 & 0 & 2 & 10 & 2 & 4 & 5 & 6 & 7 & 5 & 2 & l & 1 & 1 & 19 & 3 \\
\hline CAI: Miscellaneous & 0 & 0 & 0 & 0 & 0 & & 0 & 0 & 0 & 0 & 3 & 2 & 6 & 5 & 9 & 2 \\
\hline $\begin{array}{l}\text { Psychiatry, clinical } \\
\text { psychology, therapy }\end{array}$ & 0 & 0 & 0 & 0 & 1 & 2 & 9 & 11 & 13 & 9 & 16 & 10 & 6 & 5 & 45 & 8 \\
\hline $\begin{array}{l}\text { Biology, medicine, } \\
\text { neu rophysiology, } \\
\text { EEG, EKG, etc. }\end{array}$ & 0 & 0 & 2 & 10 & 1 & 2 & 14 & 18 & 9 & 6 & 21 & 13 & 12 & 10 & 59 & 10 \\
\hline $\begin{array}{l}\text { Simulations of learn- } \\
\text { ing, perception, } \\
\text { memory }\end{array}$ & 1 & 9 & 1 & 5 & 10 & 20 & 7 & 9 & 11 & 7 & 6 & 4 & 7 & 6 & 43 & 7 \\
\hline $\begin{array}{l}\text { Simulations of } \\
\text { social behavior }\end{array}$ & 0 & 0 & 0 & 0 & 0 & 0 & 2 & 3 & 6 & 4 & 4 & 2 & 3 & 3 & 15 & 3 \\
\hline $\begin{array}{l}\text { Simulation of social } \\
\text { system and group } \\
\text { behavior }\end{array}$ & 0 & 0 & 0 & 0 & 1 & 2 & 1 & 1 & 4 & 3 & 4 & 2 & 1 & 1 & 11 & 2 \\
\hline $\begin{array}{l}\text { Data analysis: } \\
\text { program }\end{array}$ & 0 & 0 & 3 & 16 & 14 & 28 & 12 & 15 & 14 & 9 & 21 & 13 & 20 & 18 & 84 & 15 \\
\hline $\begin{array}{l}\text { Data analysis: } \\
\text { miscellaneous }\end{array}$ & 0 & 0 & 2 & 10 & 4 & 8 & 2 & 3 & 15 & 10 & 7 & 4 & 1 & 1 & 31 & 6 \\
\hline $\begin{array}{l}\text { Man-machine } \\
\text { interaction }\end{array}$ & 0 & 0 & 0 & 0 & 0 & 0 & 2 & 3 & 6 & 4 & 2 & 1 & 5 & 4 & 15 & 3 \\
\hline Cybernetics & 0 & 0 & 0 & 0 & 1 & 2 & 0 & 0 & 2 & 1 & 12 & 7 & 13 & 11 & 28 & 5 \\
\hline Research: General & 1 & 9 & 1 & 5 & 5 & 10 & 4 & 5 & 1 & 1 & 8 & 5 & 9 & 8 & 29 & 5 \\
\hline $\begin{array}{l}\text { Bibliographies, texts, } \\
\text { discussions, readings }\end{array}$ & 16 & 54 & 2 & 10 & 3 & 6 & 4 & 5 & 2 & 1 & 5 & 3 & 4 & 3 & 28 & 5 \\
\hline Miscellaneous & 1 & 9 & 4 & 21 & 4 & 8 & 12 & 15 & 31 & 20 & 27 & 16 & 8 & 7 & 33 & 11 \\
\hline Total & 11 & 100 & 19 & 100 & 49 & 100 & 79 & 100 & 150 & 100 & 167 & 100 & 104 & 100 & 575 & \\
\hline
\end{tabular}


systems and small group processes. This absence of computer applications to social psychological research seems likely to reflect "culture lag," i.e., the underdeveloped state of the field, rather than a lack of of possibilities. Some of these are suggested below.

\section{COMPUTER-COMPATIBLE FUNCTIONS OF THE SOCIAL PSYCHOLOGIST: A SURVEY OF USEFUL APPLICATIONS}

\section{Pre-Experimental Functions}

\section{Generality of Stimuli}

Computers could be programmed to generate a large variety of visual and auditory patterns. In some cases, this would be more efficient than manual generation, in other cases, merely more interesting (see Harrison, 1973).

\section{Experimental Design}

Computers could be used to generate various possible experimental designs, to suggest the most appropriate design given an analysis of the problem and other information, and in cases of counterbalanced designs, Latin squares, and Youden squares, to make random or systematic assignments to treatment conditions.

\section{Letters to Ss}

There is no reason the computer, having assigned Ss to condition, couldn't prepare a letter to each, with their name inserted in various places, and make up mailing stickers. These letters to Ss would give each $\mathrm{S}$ his or her experimental time and place.

\section{Experimental Functions}

In general, the prime experimental function of the computer is to serve as surrogate for $\mathbf{E}$ and/or one or more Ss. The degree to which the function of $\mathrm{E}$ and/or $\mathrm{S}$ is simulated may be seen as two independent dimensions along which experiments may be ordered.

The principle advantage of simulating the performance of either $\mathrm{E}$ or $\mathrm{S}$ is to provide greater standardization hence control variability of these behaviors, consequently enhancing the strength of the experimental manipulations. In general, replacing Ss with computer simulations of their behaviors will reduce mundane realism while concomitantly increasing experimental control. The tradeoff may not always be desirable.

There seems to be little reason for not simulating the behavior of E. Presumably, E's presence is not related to mundane realism. Consequently, the following categories are outlined only for positions along the S-simulation dimension.

\section{Full Simulation for All Ss}

There are a large number of examples of this in the literature (see Apter, 1970). In general, full simulations are no better than the assumptions on which they are based.

\section{Full Simulation of All but One S, No Simulation of That $S$}

This design might be put to good use wherever one desired to run one $S$, and convince him that he was one of a number of Ss being run, yet have full control over the other "S's" behavior. This may be the most useful design for social psychological research.

Interaction Between Ss Simulated (Examples Abound). Any conformity research using the Crutch field apparatus can be done using the on-line computer, and done much better. The same goes for all game theory research (cf. Burnett, 1971), and studies of communication networks.

No Interaction of (Real or Simulated) Ss. Again, useful applications are abundant: One can simulate man-machine interaction, as David Payne is doing at Syracuse University in his study of gambling. One can study man-environment interaction. For instance, questionnaire studies of personal space could be done with a display screen; affective and exploratory response to novelty could easily be done (cf. the experiments reported here); physiological response to auditory-induced stress and related research in the general area of environmental psychology could be fully controlled by the computer.

\section{Limited Simulation of Ss}

One might choose to permit some real responses-i.e., interaction between several Ss, while simulating other parts of the experiment, other phases of the interaction. This would add mundane realism to fuller simulations, yet give better control than nonsimulations.

\section{No Simulation of Ss}

Again, assuming full simulation of $E$, one could control $E$ effects with this design, as well as making experimentation more economical of E's time. Examples include administration of clinical tests to patients, presentation of various messages in attitude change studies, and administering of surveys, questionnaires, etc., to Ss.

\section{Post-Experimental Functions}

These functions are merely listed, since most are already fairly common: data storage and retrieval; data analysis, report generation and indexing; report storage and retrieval; postexperimental questionnaire administration (in multiple choice format and/or essay format with content analysis program) Robinson (1973) reviews the many possibilities for this application; pooled-experiments analysis [a high degree of standardization in experimental design might permit running one condition at a time in factorial designs, designing the experiment (e.g., dosage levels to be examined) as the experiment progressed], and then 
analyzing it, confounding only history in the design. Cross-experiment analyses have been performed previously (e.g., Stang, 1973a, b; Stang, in press b) and are feasible when experimental design is highly standardized.

While many of the expected uses of the on-line computer in social psychological research will undoubtedly involve a "deaf" computer, which responds only to the fact that $\mathrm{S}$ has interacted, rather than to the nature of the interaction, programming for full interaction seems possible (see Rapoport, 1964) and would provide a worthwhile if arduous test of the assumptions underlying a given simulation model.

In spite of the bright possibilities, researchers are cautioned to proceed carefully, comparing results of experiments with real and simulated Es and Ss, before plunging into simulation-only research. ${ }^{4}$ These comparisons will be useful in learning when and why differences in method produce differences in results. Ultimately, these new techniques will contribute not only to our knowledge of social behavior, but to our knowledge of man-machine interaction and the social psychology of the psychology experiment.

\section{REFERENCES}

Allport, F. H. The J-curve hypothesis of conforming behavior. Journal of Social Psychology, 1934, 5, 141-183.

Apter, M. J. The computer simulation of behavior. New York: Harper \& Row, 1970.

Burnett, J. D. Component curve analysis of student performance on computer-based simulation game. Alterta Journal of Educational Research, 1971, 17, 117-128.

Edney, J. J. Place and space: The effects of experience with a physical locale. Journal of Experimental Social Psychology, 1972, 8, 124-135.

Fechner, G. T. Vorschule der Aesthetik. Leipzig: Breitkopf und Härtel, 1876.

Gilliland, A. R., \& Moore, H. T. The immediate and longtime effects of classical and popular phonograph selections. Journal of Applied Psychology, 1924, 8, 309-323.

Hamid, P. N. Exposure frequency and affect. Unpublished doctoral dissertation, University of Waikato, Hamilton, New Zealand, 1972.

Harrison, A. A., \& Crandall, R. Effects of exposure frequency and esposure sequence on immediate and delayed affective ratings. In M. P. Janisse (Chairman), The mere exposure phenomenon revisited. Symposium presented at the annual meeting of the American Psychological Association, September $1972 a$.

Harrison, A. A., \& Crandall, R. Heterogeneity-homogeneity of exposure sequence and the attitudinal effects of exposure. Journal of Personality \& Social Psychology, 1972b, 21 234-238.

Harrison, G. The computer in psychology experiments. In M. J. Apter and G. Westby (Eds.), The computer in psychology. New York: Wiley, 1973.

Maslow, A. H. The influence of familiarization on preference. Journal of Experimental Psychology, 1937, 21, 162-180.

Maslow, A. H., \& Mintz, N. L. Effects of esthetic surroundings: I. Initial effects of three esthetic conditions upon perceiving "energy" and "well-being" in faces. Journal of Psychology, $1956,41,247-254$.

McClintock, C. G. Instrumentation in social psychology. American Psychologist, 1969, 24, 283-286.

Meitzer, $H$. The content of industrial psychology in Psychological Abstracts 1927-1970. Professional Psychologist, $1973,4,321-328$.
Messick, D. M., \& Rapoport, A. Computer-controlled experiments in psychology. Behavioral Science, 1964,9. 378-382.

Mintz, N. L. Effects of esthetic surroundings: II. Prolonged and repeated experience in a "beautiful" and "ugly" room. Journal of Psychology, 1956, 41, 459-466.

Pepper, S. C. Changes of appreciation for color combinations. Psychological Reports, 1919, 26, 389-396.

Phares, E. J., \& Rotter, J. B. An effect of the situation on psychological testing. Journal of Consulting Psychology, $1956,20,291-293$

Rapoport, A. Sequential decision making in a computer controlled task. Journal of Mathematical Psychology, 1964, 1, $351-374$.

Robinson, J. O. The computer in clinical psychology, In M. J. Apter and G. Westby (Eds.), The computer in psychology. New York: Wiley, 1973.

Rosenthal, $K$. The effect of the experimenter on the results of psychological research. In B. A. Maher (Ed.), Progress in experimental personality research. Vol. 1. New. York: Academic Press, 1964.

Stang, D. J. Stimulus differences, rating delay, exposure sequence, and mere exposure: An analysis of previous research. Paper presented at the Social Psychology Graduate Student Conference, University of Michigan, Ann Arbor, March 1973a.

Stang, D. J. Theories of novelty and affect: An empirical evaluation. (Doctoral dissertation, Syracuse University, 1973b). Ann Arbor: University Microfilms 74-8313.

Stang, D. J. The effects of mere exposure on learning and affect. Journal of Personality \& Social Psychology, in press a.

Stang, D. J. Intuition as artifact in mere exposure studies. Journal of Personality \& Social Psychology, in press b.

Stang, D. J. Six theories of repeated exposure and affect. JSAS Catalog of Selected Documents in Psychology, 1973, 3, 126 (c).

Swap, W. C. The effects of repeated exposure of meaningful stimuli on attitude formation and change. (Doctoral dissertation, University of Michigan) Ann Arbor, Mich. University Microfilms, 1970. No. 71-15, 323.

Uttal, W. R. Buggywhips, whalebones, and clipboards: Some notes on generating complex stimuli with small computers. American Psychologist, 1969, 24, 202-206.

Valentine, C. W. The method of comparison in experiments with musical intervals and the effect of practice on the appreciation of discords. British Journal of Psychology, 1914, 7, 118-125.

Verveer, E. M.. Barry, H., \& Bousfield, W. A. Change in affectivity with repetition. American Journal of Psychology, $1933,45,130 \cdot 134$.

Washburn, M. F. Child, M. S., \& Abel, T. M. The effects of immediate repetition on the pleasantness or unpleasantness of music. In M. Schoen (Ed.), The effects of music. New York: Harcourt, Brace, 1927. Pp. $199-210$.

Zajonc, $R$. B. The requirem ents and design of a standard group task. Journal of Experimental Social Psychology, 1965, 1 , 71-88.

Zajonc, R. B. The attitudinal effects of mere exposure. Journal of Personality \& Social Psychology Monograph Supplement, $1968,9,1-27$.

\section{NOTES}

1. Stang, D. J. Unpublished manuscript entitled "Response competition, recall, meaning fulness, and affect."

2. For instance, J. Brockner's unpublished manuscript entitled "The effect of exposure and attitudinal similarity on self-disclosure and licking," Tufts University, 1973; Stang \& Campus, unpublished manuscript entitled "Exposure duration as a confounding methodological factor in projective testing," Queens College, CUNY. 1973; Stang \& Cooper, unpublished manuscript entitled "A theory of campaign spending and voting behavior," Queens College, CUNY, 1973.

3. A more exact description of the procedure is the FORTRAN program which ran the experiment. It may be found in Stang $(1973 \mathrm{~b})$.

4. For instance, a cautionary note is provided by the work of V. Rezmovic at Syracuse University. In a comparison of computer vs paper and pencil measures of various traits, whether one takes the computer or the paper test first seems to affect the correlation between traits. Implications of this finding are still being investigated. 